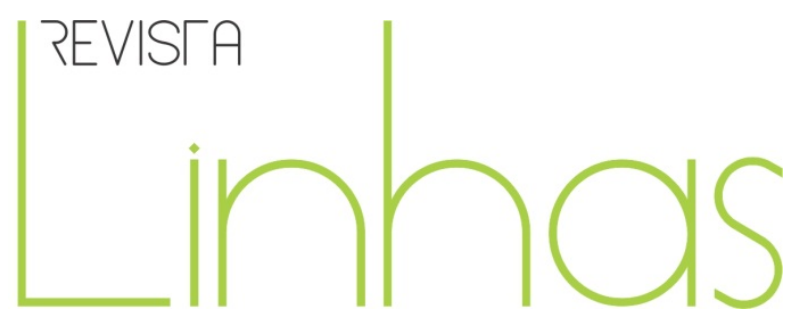

\title{
Domínio e cultura informática na escola
}

\begin{abstract}
Resumo
O presente trabalho é uma investigação a respeito da presença da informática no espaço da escola, e de como ela se constitui no âmbito das práticas pedagógicas. Para isso são identificados os papéis dos principais agentes envolvidos neste processo: alunos, professores e ainda um outro, nem sempre lembrado: o profissional de informática "residente" na escola. É a partir do olhar desse profissional que se elabora o presente trabalho, desenvolvido em duas linhas de investigação: a observação do espaço da escola e a escuta dos seus integrantes, e uma redescoberta da trajetória do profissional de informática que se encontra na escola, muitas vezes sem uma consciência clara das implicações da sua presença nesse espaço, buscando uma efetiva utilização da informática na educação. A partir disso, o texto se desdobra num olhar reflexivo do profissional de informática sobre a própria prática pedagógica, na tentativa de contribuir para concretizar a relação entre a Informática e a Educação. A intenção primeira do trabalho é apontar para a necessidade de cada instituição construir seus próprios usos e significados para a informática, bem como encontrar a partir do coletivo, soluções para questões hoje ainda em aberto. Para tal, a cultura informática é apresentada em suas variadas dimensões, numa tentativa de criar um panorama da realidade da informática na escola atual.
\end{abstract}

Palavras-chave: Informática educacional. Domínio tecnológico. Cultura informática. Profissional de informática.

\author{
Adão Caron Cambraia \\ Doutorando em Educação pela \\ Universidade de ljuí - UNIJUí, \\ Professor do Instituto Federal \\ Farroupilha. \\ cambraia@sa.iffarroupilha.edu.br
}

\section{Para citar este artigo:}

CAMBRAIA, Adão Caron. Domínio e cultura informática na escola. Revista Linhas, Florianópolis, v. 14, n. 27, jul./dez. 2013. p. $105-133$.

DOI: $10.5965 / 1984723814272013105$

http://dx.doi.org/10.5965/1984723814272013105 


\title{
Informatics culture and domain in the school
}

\begin{abstract}
The present work is an investigation about the presence of the Computer Sciences in the school, and about the way it is constituted within the pedagogical practices. In order to do so, it is identified the roles of the main agents implicated in this process: students, teachers, and another one who is not always remembered - the professional of Computer Sciences working for the school. It is form the point-of-wiew of this professional that this work is elaborated. It is developed according to two approaches: by the observation of the space of the school and by listening to the voices of its integrants, and by a rediscovery of the trajectory of the professional of Computer Sciences who works for the school, who is, in many times, not clearly aware about the implications of his/her presence in this space, searching for an effective use of the informatics in the education. Having this point stated, the text displays a reflective view by the professional in Computer Sciences about his own pedagogical pratice, trying to concretize the relationship between the Computer Sciences and Education. The prime intention of this work is to point out the necessity of each institution to construct its own uses and meanings towards informatics, as well as to find, from the collective, answers for the questions wich remain still unanswered. To this, the informatics culture is presented in its varied dimensions, in a attemp to create a new scenery of the reality of the Computer Sciences within the school these days.
\end{abstract}

Keywords: Computer Sciences. Education.

Technological domain. Informatics culture. Profissional of Computer Sciences. 


\section{Introdução}

A divisão do conceito cultura informática em três gêneros de menor abrangência (produção intelectual, alfabetização tecnológica e matriz sociotécnica) tem a intenção de facilitar o trabalho de identificar como a cultura informática se manifesta nas escolas de Educação Básica. Também visa a compreender a diversidade das dinâmicas que aparecem quando se deseja promover uma maior socialização das TIC.

Enquanto acompanhamos os desdobramentos do desejo de uma utilização crescente das TIC na educação, com todas as suas tensões e dificuldades, entramos em contato com um sentimento de mistificação, fruto da ausência de um contato mais fértil entre o que seria próprio de uma ciência da computação e a prática cotidiana da informática, inclusive o desenvolvimento de tecnologias. Através do conceito de cultura informática como produção intelectual, caracterizamos então este movimento da ciência da computação, iniciado no formalismo matemático, e suas diversas transformações. Caberá a todos nós acompanhar, no futuro que se anuncia, a trajetória de aproximação entre teoria e prática e suas dificuldades.

A respeito da cultura informática relativa à alfabetização tecnológica, descrevemos como ocorre essa alfabetização nos diversos locais onde é realizada. Caracterizamos, assim, as diferentes atitudes e exigências com que cada indivíduo se depara, conforme o contexto em que se encontra. Dessa forma, apresentar como a alfabetização tecnológica é oportunizada serve para entender um conceito de alfabetização diferente, que se define com dificuldade, pois cada pessoa tem necessidades diferentes em relação a esses equipamentos, dando lugar, consequentemente, a uma ideia de alfabetização que não é exatamente um ideal de universalidade, mas que, desde o início, também apresenta traços de especificidade.

A cultura informática também possui uma dimensão mais ampla, que afeta o cotidiano, até mesmo de quem não tem contato direto com estas máquinas. A cultura informática como matriz sociotécnica é uma elaboração do imaginário. Nela, o computador não pode ser comparado a outros aparelhos, pois não possui uma cena clara de utilização. Contemplar outro dispositivo eletrônico de consumo de massas qualquer 
(rádios, televisores, etc.) é contemplar imediatamente uma cena muito clara, cujas ações têm uma interpretação evidente.

Abordagens distintas, para entendermos conceitos que são de extrema importância para visualizar que direções a escola tem seguido até agora. Caminhos dotados de boa vontade e boas intenções, mas cheio de armadilhas, construídas por um discurso do domínio tecnológico que, de uma forma ou de outra, está presente na maioria das escolas, promovendo e organizando a informática educacional. Este discurso será referido na seguinte seção - que tematiza a informática educacional pelo olhar do profissional da área -, na qual tentamos acompanhar o encontro de identidades profissionais, seus entendimentos e seus percalços.

\section{Cultura informática como produção intelectual}

Dificilmente conseguimos definir uma data ou fato que marque a origem dos computadores. No entanto, é possível descrever seu nascimento pelo viés da matemática.

Com a intenção de resolver problemas propostos por matemáticos, Alan Turing (1912-1954) inventou uma máquina teórica, que é o conceito-chave da teoria da computação, porque foi utilizada alguns anos mais tarde por John von Neumann (19031957) para construir a arquitetura dos computadores modernos. Na tentativa de entender como a busca para dar à matemática uma nova fundamentação produziu uma tecnologia computacional, retornaremos ao final do século XIX e início do século XX, quando a disciplina se dividia em três matrizes: o logicismo, o formalismo e o intuicionismo.

Gottfried Wilhelm Leibniz é o pai do logicismo, que elege o cálculo lógico como instrumento necessário ao raciocínio dedutivo. Ele julgava ter encontrado uma lógica simbólica pela qual se poderiam atribuir números a determinados objetos e, ao combinálos a partir de regras, se resolveriam todos os problemas, sem margem a dúvidas. Com isso, acredita-se que os limites do mundo eram os limites da lógica, ou seja, os logicistas desejavam reduzir toda a matemática e a realidade à lógica. 
No entanto, essa tese encontrou muitas dificuldades em seu caminho, pois, ao se desejar reduzir a matemática à lógica, esbarra-se em algumas dificuldades oriundas do próprio pensamento lógico, como o paradoxo de Russel ${ }^{1}$ - que são falhas da lógica ao tentar expressar problemas da realidade -, que acaba por desestruturar o projeto logicista, tornando-o inviável, pois a lógica requer o princípio da não-contradição e o paradoxo de Russel demonstra que esse princípio é impossível para a matemática e a realidade.

Já os formalistas, conforme Lévy (1998a), queriam utilizar a lógica como método para obter conclusões com qualquer argumento e conteúdo. O formalismo é constituído por termos primitivos que compõem regras para a formação de fórmulas, axiomas ou postulados, regras de inferência e teoremas. Os termos primitivos descrevem os objetos empíricos da teoria. As regras de formação de fórmulas organizam o discurso a respeito desses objetos; são os axiomas. As regras de inferência determinam as inferências legítimas e distinguem, dentre as fórmulas, as que constituem os teoremas, que são verdades demonstráveis a partir dos axiomas, ou seja, a aplicação estruturada da própria lógica.

Dessa forma, a sintaxe de um sistema formal faz referência somente às suas características internas. Dentre estas, destacamos o problema da decidibilidade, formulado por Hilbert. Na época, esse matemático formulou um total de 23 problemas para nortear as pesquisas das próximas gerações. Dentre esses, o décimo problema (problema da decidibilidade), que consistia em indagar sobre a existência de um procedimento mecânico para determinar se todos os enunciados matemáticos poderiam ser ou não verdadeiros. Em outras palavras, perguntava se existe um procedimento finito que garanta se determinado enunciado aritmético poderia ou não ser provado.

Com a intenção de produzir uma prova para o problema da decidibilidade de Hilbert, Gödel usa os recursos da própria lógica para demonstrar a indecidibilidade do problema e a impossibilidade do programa formalista: "é das entranhas da lógica formal que nasce a contradição que a nega, filha rebelde que promete novos passos na dança do

\footnotetext{
${ }^{1}$ Ver Tenório (2001, p. 42) e Machado (1994, p. 27).
} 
conhecimento" (TENÓRIO, 2001, p. 46). Assim, os matemáticos começam a identificar falhas no sistema euclidiano, uma vez que se descobre que certos postulados de sua teoria não são em nada necessários e podem muito bem ser substituídos por outros, nãoeuclidianos.

Os postulados não-euclidianos reforçam o intuicionismo, que são "construções de entidades abstratas, a partir da intuição do matemático" (MACHADO,1994, p. 40), que não depende do mundo das ideias (platônico), como o logicismo, nem emerge do mundo empírico, como o formalismo, fazendo com que constitua um mundo à parte. Essa é a principal crítica ao intuicionismo.

Dessa forma, o logicismo, o formalismo e o intuicionismo refletem três crises da matemática, que nada mais são do que a crise da lógica formal. Então, "aprisionada, mutilada e morta em cárceres formais, qual Fênix, ressurge em meio às cinzas da lógica, a própria contradição" (TENÓRIO, 2001, p. 48), pois a matemática se aproxima da realidade. Ambas são contraditórias, mas não se reduzem à lógica. Segundo Lévy, "a noção de teoria dedutiva, ou também de axiomática, muda de sentido" (1998a, p. 83). Trata-se menos de construir a verdade de proposições matemáticas do que de construir sistemas perfeitamente coerentes.

O teorema de Gödel pôs fim à ambição dos matemáticos desse século; assim, as atenções se deslocam do conceito de verdade para o conceito de demonstrabilidade. Neste sentido, conforme Lévy (1998, p. 84), “Alan Turing atacou o problema da decidibilidade de um sistema capaz de formalizar a teoria dos números". Em sua solução para o problema da decidibilidade, Turing descreveu em termos matematicamente precisos como um sistema formal automático ${ }^{2}$, com regras muito simples de operação, pode ser poderoso. Quando ele uniu a matemática e a lógica na forma de uma máquina, tornou possível um sistema processador de símbolos. Criou uma definição rigorosa do conceito de algoritmo. Assim utiliza sua máquina abstrata para "provar a indecidibilidade da teoria formalizada dos números" (LÉVY, 1998a, p. 84) e ao mesmo tempo dita os fundamentos teóricos da informática ao inventar a máquina universal.

É um dispositivo que manipula automaticamente os símbolos de um sistema formal de acordo com as regras dele. 


\section{Cultura informática como alfabetização tecnológica}

Para muitas pessoas, o primeiro contato com tecnologias como o computador, internet e softwares acontece nas escolas, no trabalho, nos cursinhos ofertados por diversas empresas do ramo e, principalmente, quando se dispõem a trocar informações do meio eletrônico (ensinar e aprender sobre computadores). Na medida em que desejamos utilizar os computadores, necessitamos de um mínimo de conhecimentos sobre eles. Denominamos esse conhecimento de alfabetização tecnológica. Na época da criação do conceito, "ninguém sabia defini-lo e ninguém sabia o que era" (NOBLE apud CASEMENT \& ARMSTRONG, 2001, p. 18). De fato, cada usuário necessita de uma alfabetização diferente e, mediante inúmeras tarefas que podem ser desenvolvidas no computador, torna a alfabetização tecnológica algo pessoal - desde que seja possível transformá-la em algoritmo e traduzi-la para uma linguagem de programação.

Conforme Lévy (1993), estamos vivendo atualmente em uma época-limítrofe. Assim como a escrita, a informática também é uma tecnologia da inteligência, que gera novas relações e percepções do homem no mundo. Dessa forma, a alfabetização tecnológica é de extrema importância, não somente como simples aprendizagem de um código ou tecnologia, mas também na criação de entendimentos e significados. Assim como a alfabetização funcional (escrita e leitura) é uma questão de cidadania, a tecnológica também o é, pois ambas representam a apropriação de novas formas de elaboração do conhecimento.

A alfabetização tecnológica nas escolas e, particularmente, na região noroeste do estado do Rio Grande do Sul, é delineada pelo uso de softwares educacionais, jogos, editores de texto, editores de apresentação e uso da internet, que varia entre pesquisas, correio eletrônico, criação de blogs e sites, dependendo da escola. Evidencia-se uma ligação entre a cultura informática e a preparação para o mundo do trabalho, ainda que o lúdico e o midiático já comecem a ocupar seu espaço. O interesse por criações multimídia e internet são maneiras encontradas para unir o aprendizado das disciplinas com o uso das TIC. Pesquisa-se em livros, revistas ou internet e sistematiza-se através de slides, no 
caso dos computadores, podendo-se acrescentar elementos multimídia com o intuito de criar apresentações mais atraentes e promover uma alfabetização tecnológica de professores e alunos em torno de softwares, que são mais usados.

É preciso dizer que nem todos os professores conseguem atingir os objetivos em sala de aula com tais usos. A alfabetização tecnológica do professor de uma área não será a mesma do professor de outra área. Para a disciplina de matemática poderá priorizar um aprendizado de softwares que potencializem o estudo de sua disciplina. Da mesma forma, um professor de português, de química, de biologia. Cada um necessitará de uma alfabetização diferente.

Até mesmo no cotidiano dos programadores evidencia-se que a alfabetização tecnológica ocorre conforme a área de atuação do programador, pois a informática, "longe de evoluir em direção de uma linguagem universal, como alguns acreditaram nos anos 60, está multiplicando seus dialetos de programação, cada um deles adaptado a uma aplicação específica" (LÉVY, 1998a, p. 31). Isso demonstra que mesmo para profissionais de informática não existe uma alfabetização tecnológica universal.

Por fim, alguns usuários, na sua maioria jovens e crianças, que utilizam o computador como um hobby e têm tempo disponível, são capazes de permanecer horas diante da máquina. Eles trocam mensagens com amigos, jogam, navegam na internet ou descobrem algum segredo do meio eletrônico. Esses usuários se reúnem uns nas casas dos outros para brincar no computador. Trocam informações o tempo todo e determinam o que é importante e o que não é. Estabelecem entre si uma hierarquia de importâncias, produzem um currículo espontâneo de informática. Fazem uma seleção do que é relevante, definem uma ordem de como aprender, ou seja, criam um espaço lúdico para a troca de informações que seja agradável e crie laços de amizade e reconhecimento.

Então, a alfabetização tecnológica tem a ver com a diversidade e não com a homogeneização. Ao fazer uma analogia com a alfabetização da escrita, poderíamos afirmar que, na tecnológica, um novo alfabeto é descoberto a cada dia enquanto que outros, muitas vezes, desaparecem. Em função disso, somos obrigados a recomeçar 
nossa alfabetização tecnológica em espaços de tempo cada vez mais curtos. Trata-se de outra forma de aprender, não necessariamente mais difícil ou mais fácil do que a escrita, mas diferente.

\section{Cultura informática como matriz sociotécnica}

A indústria do século $X X$, principalmente a indústria da guerra, acabou criando as condições que impulsionaram a tecnociência na direção do mercado de consumo. A criação da tecnologia volta-se, então, sobre si mesma, tal é a intensidade com que os próprios artefatos participam da criação de novos artefatos. Conforme Tenório (2001), ao mesmo tempo em que a necessidade da indústria impulsiona a criação desses aparelhos, eles são responsáveis pelo ímpeto da produção científica, que vai interferir na produção de novos aparatos tecnológicos. Assim, a tecnologia cria novos problemas para depois solucioná-los, ou seja, a tecnologia cria usos que, anteriormente a ela, nem sequer haviam sido sonhados.

As pessoas utilizam determinados aparelhos por estarem na moda, ou seja, acompanham uma "tendência", que por sua vez alimenta o marketing estratégico e a publicidade. Em uma fase mais adiantada desse processo, as empresas podem limitar o lançamento de tecnologias novas, prolongando-lhes a permanência, embora sabendo de suas ineficiências; às vezes, lançam novos produtos, dando guinadas bruscas para o totalmente novo, como, por exemplo, a venda do Windows casada com o Internet Explorer $^{3}$, que constitui uma estratégia de mercado da Microsoft para enfraquecer suas concorrentes e controlar o mercado.

Assim, o controle dos fluxos de inovação é constituidor de cartéis, ou empresas de caráter monopolista, que organizam estes fluxos e, é claro, o mercado, que interage com eles no sentido de acelerar ou desacelerar os lançamentos de produtos. De acordo com suas possibilidades, a estratégia dessas empresas é a transformação do produto mais do que a especialização da produção (DELEUZE, 1992), que tem como princípio o exercício do controle, e não simplesmente uma aceleração cada vez maior.

\footnotetext{
${ }^{3}$ Software para navegação na internet.
} 
Dessa forma, esses artefatos, cujo propósito inicial parece ser o de sublimar o trabalho humano já existente, são, paradoxalmente, responsáveis por criar mais complexidade, pois permitem a realização de novas atividades, evidenciadas desde antes do nascimento até a vida adulta. As fronteiras entre humanos e tecnologias estão entrelaçadas, pois, conforme Lévy (1996, p. 150), “somos pegos nesse enorme salto que nossa espécie efetua em direção ao núcleo mesmo desse estranho turbilhão". Fazemos parte, com nossos corpos também, do ciclo de produção tecnológica; produzimos tecnologia e somos produzidos por ela. Antes do nascimento de uma criança, sabemos seu sexo, ouvimos seus batimentos cardíacos, inclusive olhamos como ela está e como se move dentro do útero. Ao nascer, é recepcionada em um hospital, com imensos recursos. Surpresas e imprevisões são mais difíceis de acontecer.

$\mathrm{Na}$ infância, nossos filhos brincam de forma diferente de há poucos anos. Eles jogam futebol no computador, driblam com apenas um movimento de mão sobre o mouse. Não precisamos sair de nossas casas para ir ao trabalho, para ter acesso a informações do dia-a-dia, para o lazer. A comunicação pode ocorrer em qualquer lugar e momento. A internet, bem como os celulares, permite-nos estabelecer comunicação com outras pessoas em diversos pontos do planeta. Podemos escolher a forma de comunicação desejada, seja através da fala, da escrita ou da imagem. Mudam as formas de comunicação entre as pessoas, que também "moldam e determinam a cultura" (CASTELLS, 2000, p. 354), condicionando novas formas de ser, de viver e se relacionar com os outros e com o mundo.

Para além do computador, outros aparelhos começaram a registrar aumentos no número de usuários de forma surpreendente. Conforme a Anatel ${ }^{4}$, no mês de janeiro de 2012, o País possuía 125,29 linhas de celular para cada 100 habitantes. Em 2011, 8,9 milhões de smartphones e tablets foram comercializados. O IDC (Instituto de Defesa do Consumidor) prevê para 2012 um aumento de 73\% nas vendas ${ }^{5}$. Esses índices demonstram que, ao invés de um grande número de eletrônicos afluir ao computador, transformandoo em um aparelho audiovisual multifuncional, ocorre o contrário. Novos aparelhos

\footnotetext{
${ }^{4}$ Agência Nacional de Telecomunicações, www.anatel.gov.br. Acesso em: 10 jan. 2012.

${ }^{5}$ Acesso <http://www1.folha.uol.com.br>, em: abr. 2012.
} 
surgem para substituir tarefas "mais populares" do computador e vão sendo sofisticados de tal forma que cada vez mais se ajustam a nossas vidas. A computação evolui para além do computador.

\section{A informática educacional pelo olhar do profissional de informática}

A presença do discurso do domínio tecnológico faz com que o profissional de informática, no âmbito educacional, mascare o desejo e anule a liberdade de cada usuário, que são os alicerces para o processo de criação e inovação na informática, pois, ao assumir esse discurso, formula receitas para que possamos obter uma eficiente utilização das TIC. Notamos, então, que, ao invés de adaptar a informática aos nossos desejos, nós nos adaptamos a ela, porque, para utilizá-la, recebe-se um manual de instruções. Esquecemos de questionar o que queremos com as TIC na educação. Com isso, as necessidades são produzidas para que possamos utilizar computadores.

Analisar caminhos que o discurso do domínio constrói para a utilização do computador proporcionará aos professores uma compreensão da atual relação entre a informática e a educação. O resgate de como essa aliança foi se constituindo tem a intenção de recuperar aspectos que, por diversos motivos, foram esquecidos ou simplesmente deixados para trás, ajudando-nos a reconhecer que o profissional de informática é um dos porta-vozes do discurso que convoca a comunidade escolar a se empenhar em uma corrida por constantes atualizações tecnológicas.

Esse profissional é recebido na escola com a incumbência de promover a utilização das TIC. Ele simplesmente está cumprindo o papel que lhe foi atribuído, qual seja, o de disseminar o domínio tecnológico. A escola tem expectativas em relação às TIC e ele é o responsável por superá-las. A todo o momento, precisa trazer novas ideias de como melhor utilizá-las na educação, bem como propor a aquisição de novas tecnologias com a intenção de, cada vez mais, melhorar a estrutura existente que, segundo esse discurso, aprimoraria a qualidade da educação.

Com a intenção de entender a constituição da informática educacional, elencamos um conjunto de aspectos que o discurso do domínio obriga os envolvidos nesse processo 
a realizar. De um lado, a necessidade de cumprir funções pré-determinadas pelo domínio, que em muitos momentos se confronta com o papel da educação, que deseja formar cidadãos produtores de conhecimento. De outro, ao invés de serem considerados os aspectos culturais mais amplos que o computador pode produzir, quando tomadas pelo discurso do domínio, as TIC passam a ser vistas apenas como máquinas de ensinar. A seguinte descrição servirá para entendermos como se constituiu esse panorama na informática educacional.

\subsection{A máquina não possui uma cena clara de utilização}

A valorização do domínio tecnológico faz com que o profissional de informática seja visto como o grande conhecedor de TIC, e é, na medida em que encarna esse papel, reconhecido e aceito no espaço da escola. Perde, inclusive, a conta de quantas vezes é requisitado para resolver problemas em computadores. Uma pesquisa patrocinada pela Siemens Business Services ${ }^{6}$ mostra que $36 \%$ dos funcionários de escritório gastam cerca de 30 minutos por semana ao telefone tentando resolver problemas nos computadores; $20 \%$ gastam 1 hora ou mais e $5 \%$ dizem gastar em torno de 5 horas.

O resultado dessa pesquisa ilustra nossas dificuldades em utilizar os computadores. É uma realidade de muitos locais que desejam utilizar esses equipamentos, não sendo diferente na escola. Alguns problemas são resolvidos em instantes, o que já causa um certo impacto (“o que você fez?” — "ih, eu fiz isso e não deu certo"). Outros não, pois o profissional de informática nem sempre sabe do que se trata ou tem condições técnicas de encaminhar uma solução. Mas, devido ao discurso do domínio, dificilmente ele admitirá seus limites. Ele pensa em outras alternativas e acaba, de uma forma ou outra, resolvendo ou sugerindo maneiras de solucionar os problemas que surgem, ou de apenas conformar-se com eles.

Nesta distribuição de papéis, certa dependência corresponde ao usuário leigo, pois necessita da presença do profissional de informática nos momentos em que serão executadas novas ações com os equipamentos. A presença do discurso do domínio em

\footnotetext{
${ }^{6}$ Acesso em <http://www1.folha.uol.com.Br/folha/informática/ult124u16580.shtml>: 21 abr.2012.
} 
um espaço pedagógico pode ser antipedagógico (a tecnologia é enxertada, não apropriada). Qualquer nova tarefa que se deseje executar, mesmo para um usuário experiente, pode ser extenuante, que dirá para um neófito! Os detalhes exigidos para se alcançar determinados objetivos são difíceis de registrar. Portanto, a presença do profissional de informática é a "garantia" de que a tecnologia funcionará bem, pois, geralmente, tem mais conhecimentos técnicos, o que dá aos demais professores a segurança desejada. Esse profissional é requisitado até mesmo para participar de algumas socializações de trabalhos que exploram o uso do computador.

Esta assessoria não termina na ajuda com conhecimentos técnicos; requisita-se a participação do profissional de informática para auxiliar na proposição de atividades a executar, de projetos a desenvolver com tais equipamentos. Com essa finalidade, são organizados quadros informativos, em que se descrevem exemplos de como utilizar determinadas tecnologias na educação. Também se promovem capacitações para professores, explicando algumas possibilidades de usos educacionais. Mas, conforme Pesquisa Nacional da UNESCO (2004, p. 98), somente 1,5\% dos professores brasileiros participam de listas de discussão através do correio eletrônico; 89,3\% afirmam nunca ter utilizado determinada tecnologia. Já 7,3\% dos professores afirmaram navegar diariamente na internet. Ao mesmo tempo, a pesquisa divulga que $49,5 \%$ dos professores possuem computadores em suas residências e, desses, 73\% possuem internet. Fica evidente que o baixo índice de utilização das TIC não se dá apenas devido à não-disponibilização do equipamento. A comunidade escolar não o usa porque não sabe o que fazer com o computador.

Tendo em vista essa realidade, o profissional de informática assume as suas responsabilidades e pensa o que pode ser desenvolvido no laboratório de informática, produzindo alternativas de uso para as diversas áreas do conhecimento.

Ocorre uma espécie de transmissão de cenas de utilização, pois o discurso do domínio faz com que seus representantes imaginem o que cada professor necessitará e, a partir disso, descrevam como ele e seus alunos poderão utilizar as TIC. Elimina-se, dessa forma, a possibilidade de os próprios professores desenvolverem esse processo de produção de cenas, que "equivale a utilizar de maneira original elementos preexistentes" 
(LÉVY, 1993, p. 58). Ao produzir caminhos para que os demais usuários possam trilhar, substitui o espaço de uso e a criação que, conforme Lévy (1993), são “complementares e permitem a criação de novos usos e significados". Pela descrição desses novos usos e significados - dos quais fornece a receita -, impede a ampliação da rede de usos e significados e obriga as pessoas a se adaptar às tecnologias.

Diante desse fato, diversas são as reações: há os que se satisfazem com tais usos e centram seu trabalho nessas cenas, pois a digitação, a busca de informações (que alguns professores chamam de pesquisa na internet) e a confecção de apresentações de trabalhos podem ser utilizadas em diversas áreas do conhecimento. Muitos acabam se frustrando, afastando-se das tecnologias, talvez devido aos tipos de cenas conhecidas que não justificam sua utilização em sala de aula. Há também os que se mantêm afastados, mas vislumbrados com o "novo". Ainda existem os usuários que desejam produzir formas de utilização específicas de suas áreas e encontram dificuldades; buscam, então, alternativas para possibilitar maior "compreensão" das TIC. Tais usuários frequentam cursos de informática e criam, assim, uma maior dependência do discurso do domínio e das soluções milagrosas que oferece, como, por exemplo, proporcionar mais ludicidade na educação pela disseminação e uso das TIC.

\subsection{O discurso do domínio induz uma associação entre educação e entreterimento, ao invés da ludicidade}

Em todos os momentos de nossas vidas, e não apenas na escola, "o desenvolvimento do aspecto lúdico facilita a aprendizagem, o desenvolvimento pessoal, social e cultural, [...] facilita os processos de socialização, comunicação, expressão e construção do conhecimento" (SANTOS, 1997, p. 12). Considerando isso, é consensual o desejo de estimular maior ludicidade na educação.

Neste sentido, a escola facilmente segue o discurso do domínio, que prioriza a disponibilização de gadgets, com a intenção apenas de satisfazer os alunos. Muitas vezes, de uma minoria. Assim, proporciona maior interesse pelos estudos, porém, frequentemente, de forma artificial (CASEMENT \& ARMSTRONG, 2001). Adquire-se um 
software educacional pelo fato de ser mais divertido, ainda que simplesmente reproduza os antigos programas de exercício e prática. São propostos trabalhos na internet em momentos de aula, mesmo sabendo que a maioria dos alunos acessam sites apenas de entretenimento e realizam a pesquisa rapidamente, ou em outros momentos, para em aula navegarem livremente.

Além disso, para comprovar o “funcionamento” da informática na escola, esse discurso direciona a utilização de computadores para realizar apresentações de trabalhos, priorizando o aspecto mais animado das apresentações, promovendo uma corrida para a reserva de materiais audiovisuais, com a intenção de socializar tais sistematizações. Essa é uma ótima via para conquistar mais adeptos, direcionando as atenções para o aspecto mais atrativo e divertido das apresentações. A motivação impulsionada pelo vislumbre de tais ferramentas é quase automática.

Mas essa motivação forçada, e induzida, não tem nada de lúdico, pois "a essência do espírito lúdico é ousar, correr riscos, suportar a incerteza e a tensão" (HUIZINGA, 1993, p. 59). Quem traça caminhos para automatizar o ensino, arrisca-se a abortar todo o lúdico que a própria informática poderia proporcionar. Esquecemos que a ludicidade é uma necessidade para nossas vidas, que não pode ser confundida com diversão.

Conforme Huizinga (1993, p. 8), “o puro e simples jogo constitui uma das principais bases da civilização"; é um fenômeno cultural. Segundo o autor, algumas de suas características são: ser livre, ele próprio liberdade; não é vida real (toda criança sabe quando está 'só fazendo de conta'); desinteressado (está fora da satisfação imediata das necessidades e dos desejos); o isolamento, a limitação (de tempo e espaço) e a ordem (necessidade de construir regras).

Não é, pois, todo jogo que tem um caráter lúdico. Em muitos momentos, propomos um determinado jogo e explicamos todas as regras; colocamos cada aluno em posição; damos as ordens e as crianças executam apenas os movimentos mecânicos. Com essas ações, podemos anular a ludicidade do jogo e eliminar a possibilidade de as crianças reconhecerem o outro, dialogarem e construírem as regras para determinada atividade. A escola, ao consentir com essa atuação, ao invés de propiciar um ambiente lúdico, induz 
justamente o contrário. Simplesmente disponibilizar um jogo não-lúdico pode ser uma forma de passar o tempo, enquanto a educação não acontece. Neste cenário, o professor realmente está ausente da relação pedagógica. A situação se agrava quanto maior for o número de alunos que compartilham a mesma sala de aula.

\subsection{Para o discurso do domínio não importa o número de alunos em sala de aula}

Atualmente, é cada vez mais comum encontrar turmas com o maior número de alunos possível. Isso dificulta ao professor acompanhar individualmente as necessidades e deficiências de cada estudante para possibilitar uma produção do conhecimento, pois a comunicação em sala de aula se torna quase impossível. Não se constituem, e não existem, as mínimas condições de o professor poder, de acordo com Demo (2004), cuidar da aprendizagem de seus alunos. Assim, em muitos momentos, o professor não vê alternativas de organização do grupo que não sejam apenas aulas expositivas, nas quais ele atua como o único detentor do conhecimento e os alunos são apenas ouvintes. Turmas muito numerosas dificilmente permitem o desenvolvimento de qualquer outro tipo de atividade. O professor acaba optando por manter o máximo de silêncio, expondo o tempo todo o máximo de informações possível.

O discurso do domínio, aproveitando-se dessa situação, afirma que o computador permite que cada aluno avance de acordo com suas próprias necessidades, bastando possuir um software que atinja os objetivos propostos. Segundo esse discurso, quando o aluno está em frente ao computador e segue passos para executar determinadas tarefas, pode avançar nos exercícios e retornar quantas vezes quiser. Revela, assim, que os antigos softwares de exercício e prática continuam sendo muito usados. Evoluíram bastante, no sentido de serem mais atrativos e capazes de prender por mais tempo a atenção das crianças, já que misturam educação e entretenimento.

Sem dúvida, o computador pode dar uma maior percepção do desenvolvimento individual do aluno, pois o professor precisará ouvi-lo. Na medida em que as crianças têm acesso a um meio pouco estruturado e abundante de informações, ou seja, a criança traz 
a informação e vai dizer para o professor: "olha o que eu fiz", "olha o que eu trouxe" ou “veja essa informação, que interessante", exige que o professor tenha uma maior habilidade de escuta. O professor estará se colocando no lugar de quem orienta e estimula os alunos a continuar falando. A utilização das TIC na educação provoca, de certa forma, uma extensão da Educação Infantil para os próximos anos da Educação Básica, no sentido de necessitar de um professor que tenha habilidade muito maior em ouvir e observar que a de pautar inteiramente o que acontece.

Ao mesmo tempo em que o número de alunos por turma é ampliado, exige-se mais tempo para que o professor possa acompanhar mais de perto os alunos. Neste sentido, cria-se uma tensão entre este maior cuidado por parte do professor e a gestão financeira do espaço da escola, que aponta para uma segmentação social da aplicação de tecnologias à educação. Em outras palavras, as escolas que conseguem oferecer melhores condições de trabalho proporcionam a singularização, isto é, criam condições para que os professores possam realmente observar e ouvir cada aluno. Mas, aquelas que enfrentam diariamente problemas de todas as ordens acabam massificando a utilização das TIC.

\subsection{O domínio é responsável pelo aumento de trabalho dos docentes, mesmo quando prevê sua redução}

Participando dos diferentes espaços da escola e vivenciando-os, não precisamos de muito esforço para notar a sobrecarga de trabalho de muitos professores. Dificilmente conseguem dar conta de seus afazeres dentro do tempo de que dispõem na escola. De acordo com a Pesquisa Nacional da Unesco:

a situação que os professores mais consideram como um problema para o
exercício de suas atividades é o tempo disponível para a correção de provas,
cadernos, etc. (69,3\%). A segunda situação mais mencionada é o tempo
disponível para o desenvolvimento das tarefas (54,9\%) (UNESCO, 2004, p. 117).

Mesmo assim, o domínio induz aos professores a incluir informática em suas aulas, alegando que para atingir os objetivos propostos será necessário que praticamente todos os professores comecem a usar as TIC em suas aulas. Para o profissional, em alguns 
momentos, essa utilização agiliza e reduz a complexidade do seu trabalho. Com a intenção de proporcionar o mesmo para os demais professores, ele se propõe a instrumentalizar tecnologicamente o professor, descreve o que e como fazer para utilizar o computador em suas aulas.

Para isso, os professores são levados a pensar que seu trabalho será mais fácil, mais eficiente e mais produtivo quando utilizarem um computador pessoal para alcançar seus objetivos. A pesquisa da Unesco, já referida, mostra que 90,8\% dos professores acreditam que as TIC facilitarão o trabalho docente nas aulas. Mesmo que o número dos que já as utilizam (ver seção "A máquina não possui uma cena clara de utilização”) seja praticamente insignificante, isso demonstra que o discurso do domínio é eficiente entre eles e alguns acabam subentendendo atualização pedagógica apenas como atualização tecnológica.

A partir dessa concepção, resta aos professores: comprar computadores (aqueles que podem), frequentar treinamentos em informática (os melhores geralmente são caros) e depois pensar em como desenvolver suas aulas com tais equipamentos. Quem realiza trabalhos com softwares educacionais, além de aprender a usá-los, precisa fazerIhes a devida avaliação, pois são muitos, e não adianta escolher a esmo: fica sempre a interrogação sobre o que ficou de fora. O docente, preocupado com a produção do conhecimento, provavelmente, passará horas verificando e testando programas, antes de usá-los em sala de aula.

Como se isso não bastasse, o termo reciclagem é usado para designar a necessidade de atualização tecnológica do professor, conotando um possível descarte, caso essa não ocorra. Assim, ao invés de proporcionar uma atuação docente voltada à pesquisa, e que reflita sobre a prática, e que a partir disso estabeleça critérios para a produção do conhecimento no lugar de uma pedagogia da construção do conhecimento, o pensamento das TIC pode acarretar uma significativa sobrecarga de trabalho ao professor. Conforme Apple (1995, p. 161):

Mais e mais coisas precisam ser feitas, menos e menos tempo está disponível para fazê-las. Assim, não se tem uma grande escolha a não ser a de comprar materiais prontos, continuando dessa forma a tendência na qual todos os elementos curriculares não são localmente produzidos, mas adquiridos de 
fontes comerciais cuja finalidade maior pode ser o lucro e não necessariamente o mérito educacional.

Este movimento obriga os professores a deixar de produzir materiais de acordo com a cultura de que fazem parte, para adquirir materiais prontos de empresas que têm como interesse primeiro a manutenção de um mercado cativo. Prevalece a perspectiva do treinamento no lugar de uma pedagogia da produção do conhecimento.

\subsection{O domínio traz precocemente para a escola a preocupação com o mercado de trabalho}

De acordo com o discurso do domínio, a pessoa que não providenciar a sua instrumentalização tecnológica não terá lugar ou será automaticamente descartada do mercado de trabalho. Essa foi uma das primeiras bandeiras levantadas pela tecnofilia para introduzir as TIC na escola. Esse discurso foi disseminado de tal forma que é, atualmente, um dos principais argumentos ouvidos quando alguém deseja aprender sobre computadores.

Nilson José Machado (2004, p. 57) afirma que a preparação para o mercado de trabalho "tem como palavra de ordem a aplicabilidade do conhecimento [...] visando uma utilização no exercício profissional". Prevalece, portanto, para o mercado, o imediatismo dos saberes úteis. Isso se justifica, talvez, devido à disseminação da informática por diversos setores da sociedade, que pode deixar margem à ilusão de que o contato com a máquina, a familiaridade com ela equivale, coincide com acesso ao trabalho.

Para Adam Schaff (1992), entretanto, com o avanço da tecnociência e da eletrônica, ocorre uma transferência das próprias operações intelectuais para as máquinas, diferenciando-se da revolução industrial, que substituiu a força física pela força das máquinas. Nesse caso, o trabalho que o discurso do domínio coloca em primeiro plano é o das atividades físicas ou intelectuais repetitivas (para as quais basta se apropriar de alguns saberes e aplicá-los durante toda a vida). Tal domínio pode ser medido pelo número de horas trabalhadas para cálculo do salário equivalente. Esse trabalho, contudo, está se rarefazendo rapidamente. De acordo com Lévy (1996, p. 60) "a hora uniforme do 
relógio não é mais a unidade pertinente para a medida do trabalho", pois o trabalho padronizado, cada vez mais, é realizado por máquinas. Conforme pesquisa realizada pela Fundação Getúlio Vargas ${ }^{7}$, no ano de 1980, a indústria automobilística tinha um empregado para cada quinze automóveis que produzia; hoje mantém apenas um para cada 100 veículos que fabrica.

Além disso, para muitas pessoas que operam determinado software voltado à automatização de tarefas específicas da função, a instrumentalização ocorre com alguns minutos de instrução (que pode ser fornecida por um colega mais antigo), pois, geralmente, trata do domínio de alguns comandos que serão repetidos pelo resto do tempo em que o trabalhador permanecer na função. Em muitos casos, essa função também terá sido suplantada, já que os próprios clientes podem operar diretamente as máquinas, reduzindo o número de trabalhadores que atuam no atendimento ao público, como é o caso das instituições bancárias. Tais fatos revelam que, na medida em que pensamos nas TIC somente sob o aspecto de mercado, estaremos perdendo de vista a complexidade maior do fenômeno. Então, ocorre uma subordinação do mundo educacional ao mundo do trabalho.

No entanto, o discurso do domínio não leva isso em conta e traz precocemente para o Ensino Fundamental a preocupação com o mercado de trabalho. Geralmente, a situação de pobreza das famílias é o fator que mais influencia a participação de crianças e adolescentes no mercado de trabalho. A escola, ao assumir esse discurso, também impulsiona esse movimento, pois, diante do discurso do domínio, acaba por motivar os alunos a pensarem no trabalho e a nele ingressarem. O contato com os computadores passa a ser visto, quase exclusivamente, com essa finalidade.

Assim, recebemos pronto o que fazer com o computador e o transformamos em um instrumento de trabalho, pois nos são passadas ferramentas úteis para nosso cotidiano profissional. No caso do âmbito educacional, ferramentas que potencializam o ensino e as TIC não substituirão a televisão ou o aparelho de som; estarão no lugar do instrumento de trabalho. Portanto, as usaremos pelo tempo necessário para efetuar

${ }^{7}$ Revista Veja, de 17 dez. 2003, p. 179. 
nossas tarefas; no máximo, passamos alguns minutos para resolver algumas atividades profissionais. Com isso, dificilmente passaremos algum tempo livre em frente a um computador, ou seja, dificilmente conseguimos definir nossos próprios usos e significações.

\subsection{O domínio estabelece formas de controle que domesticam a interdisciplinaridade existente na hipertextualidade}

Num contexto marcado por rápidas e profundas transformações, em que o conhecimento sofre atualizações e mutações permanentes, a formação do cidadão tornase quase impensável sem uma perspectiva interdisciplinar. A ligação dos assuntos e conceitos que organizam nossas vidas estabelece como exigência a integração dos conhecimentos para a resolução dos problemas que nos desafiam. Entretanto, Fazenda (1993, p. 64) esclarece que "a atitude interdisciplinar não está na junção de conteúdos, nem na junção de métodos; muito menos na junção de disciplinas, nem na criação de novos conteúdos produto dessas junções; atitude interdisciplinar está contida nas pessoas que pensam o projeto educativo". Ou seja, a interdisciplinaridade não é algo pronto e acabado; ela contrapõe-se à ideia de linear; não se trata de um ponto a ser alcançado, pois está em constante reconstrução. Até pode, por certo tempo, se estabilizar, mas essa estabilização faz parte do planejamento do trabalho em sala de aula.

A extensão e a composição da interdisciplinaridade estão sempre em jogo para os atores envolvidos, sejam eles alunos, professores ou objetos de estudo. Tudo e todos constroem o contexto de trabalho, com ele se relacionam e dentro dele são construídas as relações de sentido. Esses atores são a heterogeneidade, pois cada ator representa a diferença.

O processo interdisciplinar organiza-se de modo fractal; qualquer novo elemento se revela composto por toda uma rede de significados, e assim por diante, indefinidamente. Então, em uma atitude interdisciplinar não existe um centro, um saber mais importante que o outro, mas pontos distribuídos, que se ramificam em infinitas raízes, que constituem outras significações e novas ramificações. 
O hipertexto é interdisciplinar. Cada informação interligada às demais forma o hipertexto, que é definido por Lévy como:

um conjunto de nós ligados por conexões, os nós podem ser palavras, páginas, imagens, gráficos ou parte de gráficos, sequência sonora, documentos complexos que eles mesmos podem ser hipertextos. Navegar em um hipertexto significa, portanto, desenhar um percurso em uma rede que pode ser tão complicada quanto possível, porque cada nó pode, por sua vez, conter uma rede inteira (LÉVY, 1993, p. 33).

O referido autor, ao tempo em que conceitua, utiliza o hipertexto como uma metáfora que contribui para compreendermos as esferas da realidade nas significações que estejam em jogo. Reforça a ideia de que, para conhecermos um texto ou darmos a ele um sentido, precisamos conectá-lo a outros textos, produzindo o hipertexto, uma grande rede de relações significativas, colaborando, assim, "para criar e recriar o mundo de significações que nós somos" (LÉVY, 1998b).

Podemos definir, então, o que Lévy (1999, p. 121) chama de "universal sem totalidade"; ou seja, "instaura-se a presença virtual da humanidade em si mesma (o universal) que não seja por meio da identidade do sentido (a totalidade)". A partir do momento em que cada vez mais computadores são conectados à internet, novas pessoas passam a acessá-la e, consequentemente, novas informações passam a fazer parte da rede. Significa que, quanto maior o ciberespaço, mais universal ele se torna e, ao mesmo tempo, menos totalizável, pois ele é desprovido de significado central, na medida em que cada integrante pode se tornar emissor e/ou receptor de novas informações, que são imprevisíveis e permanentemente transformadas.

Geralmente, o hipertexto é rizomático: pode-se sair de um determinado texto ou assunto e acessar outros, conforme desejarmos. No entanto, o discurso do domínio, através de seus representantes, estabelece formas de disciplinamento e anula a interdisciplinaridade existente na hipertextualidade, pois determina por onde podemos ou não navegar; impede que o acesso às informações flua entre as diversas áreas do conhecimento. Não mede esforços para delimitar como os computadores serão utilizados na educação; determina os sites que serão acessados por todos; constrói muros. Então, os representantes desse discurso estabelecem desde a utilização de uma enciclopédia 
eletrônica, ou software aplicativo, até a utilização da internet. As formas de uso são fixadas.

Durante a realização de pesquisas, por exemplo, determinam e verificam os sites que os alunos acessam, para se certificar de que está sendo feito o combinado. Em muitos momentos, esses profissionais permitem que os alunos escolham os assuntos para a pesquisa, mas igualmente não admitem que se saia do plano traçado. Com isso, a informática aplicada à educação não reivindica necessariamente outra pedagogia: busca compor-se, de alguma maneira, com algumas vertentes da tradição do pensamento da educação. Assim, acontece uma sobrecodificação (disciplinarização) desse espaço de não-controle; isto é, o adaptamos de forma que permaneçam e se mantenham (com alguns poucos ajustes) as teorias educacionais até esse momento vigentes e, ao mesmo tempo, possam comportar o ciberespaço.

Contudo, o próprio não-controle cria seus próprios controles através, por exemplo, do novo marketing de relacionamentos, que é capaz de captar inúmeras informações das pessoas, com a intenção de constituir banco de dados com potenciais consumidores. "São as sociedades de controle que estão substituindo as sociedades disciplinares" (DELEUZE, 1992, p. 220). É evidente que mecanismos de disciplinamento não desaparecem, mas devem compor-se com dispositivos de controle para recobrar a eficácia.

Segundo Serres (2000, web), o “não-controle é uma das principais características da sociedade pedagógica". Para explicitar, utiliza o exemplo de um grupo de médicos que desenvolveu um site que dá a palavra às mulheres que têm ou tiveram câncer de mama. Vários oncologistas aprenderam muito neste site, porque as mulheres se sentem livres para dizer o que querem, de tal forma que, às vezes, Ihes ocorre dizer coisas que são fundamentais, das quais os médicos não tinham a menor ideia. E é justamente por não haver controle que elas podem dar a informação que o médico pode achar verdadeiramente importante para sua atividade profissional.

Assim, ao invés de somente controlar o acesso, talvez devêssemos também conscientizar, pois, conforme Serres, o não-controle já era uma crítica lançada outrora às 
bibliotecas. Dizia-se: qualquer criança pode ir à biblioteca, a qualquer momento, pegar um livro e ninguém consegue controlar o tempo todo. Logo, a crítica sempre existiu e o que interessa é esse novo espaço, de não-controle, em que podemos acessar informações importantes. A internet, assim como a biblioteca, é esse espaço de não-controle; "a biblioteca, de certa maneira, salvou a humanidade por causa do não-controle" (SERRES, 2000, web); dessa forma, o não-controle é a essência do ato pedagógico.

\subsection{O discurso do domínio torna o profissional de informática indiferente à queixa}

O discurso do domínio utiliza alguns argumentos para dar impulso à utilização das TIC na escola, entre o quais: "se não começarmos a usar computadores, não vai mais dar pé”. Tal discurso coloca a utilização de computadores como uma necessidade vital para todos e literalmente risca do mapa quem não se apropria desses equipamentos, pois vê a solução de alguns problemas da educação somente a partir do uso das TIC. Então, o “computador é apresentado como um bem supremo, um atleta velocista com uma memória de elefante, capaz de proezas inimagináveis pelos pobres mortais, lentos e de memória curta" (MACHADO, 2002, p. 108).

O profissional de informática é convidado a frequentar o âmbito educacional, com a intenção de disseminar esse discurso. Diante da afirmação: “odeio o computador, não gosto de usá-lo", responde com um sinal de indiferença, pois tem a expectativa de que, cedo ou tarde, todos se submeterão à alfabetização tecnológica. Esse profissional não faz questão de ouvir as queixas, principalmente as que são contrárias à utilização de computadores por não conseguirem dar conta desta alfabetização. Os porta-vozes do domínio não sabem o que responder, ou melhor, não têm o que responder, pois esse discurso reifica as máquinas na sua limitação.

Os profissionais comprometidos com o domínio criam formas de utilização comuns ao maior número de áreas possível, para que todos os professores possam "saber" o que pode ser feito (todos podem pesquisar na internet, todos podem construir apresentações). Os problemas lançados a esses profissionais apontam para uma solução 
imediata, como, por exemplo: "como faço para ver o que tem no meu pen-drive?" ou "o que posso fazer com o tablet em minha disciplina?" A primeira pergunta operacional pode ser respondida facilmente (qualquer usuário responde); já a outra, que ninguém pode responder para o novo usuário, somente ele poderá respondê-la, mediante seu interesse pelas TIC. Mas o profissional de informática faz o máximo para respondê-las; traz softwares para aquela disciplina (instala e explica ao professor como deve usá-los) e também mostra como proceder com o pen-drive. Quem ainda não se deparou com dificuldades em definir o que fazer com o computador? Quem ainda não ficou indignado, sem saber como fazer algo no computador? E o que geralmente é feito nesses casos? Provavelmente a solução mais próxima seja o especialista em máquinas, que resolve o problema, só que não sabemos muito bem como - esse profissional não fala a mesma língua do usuário leigo! - fornece somente a solução.

Por conseguinte, com a disseminação do discurso do domínio, fica impossível a existência de alguém que faça a interface entre a produção intelectual, a alfabetização tecnológica e a cultura informática propriamente dita, ou seja, as pessoas ficam à deriva, sem saber para que lado seguir: se correm para tentar acompanhar aquilo que se apresenta como cultura tecnológica, ou se tentam atingir a alfabetização tecnológica no contato com cada objeto, pois desejam o que o domínio promete.

$\mathrm{Na}$ interação com sistemas computacionais acontece um esforço apenas do lado do usuário, pois ele sempre está procurando aprender sobre determinados softwares, que amanhã ou depois não mais existirão; com isso, os usuários, em sua maioria, atuam apenas como multiplicadores desses produtos, à medida que as diversas mudanças que ocorrem na informática exigem a todo o momento um recomeço na alfabetização tecnológica. O profissional comprometido com esse discurso não ameniza essa corrida, nem socializa um conhecimento; pelo contrário, é responsável por imprimir mais aceleração às mudanças que já são velozes. Não fornece nenhuma explicação ao usuário; apenas receitas de como executar determinadas tarefas no computador. 


\section{Para não concluir}

Atualmente, precisamos constantemente nos atualizar, pois as informações e os conhecimentos estão em intenso movimento. Seu ciclo de renovação é cada vez mais curto, proporcionando que o volume de informações duplique a cada renovação. Conforme Lévy:

até a segunda metade do século XX, uma pessoa [...] transmitia geralmente seu saber, quase inalterado, a seus filhos ou a aprendizes. Hoje, esse esquema está em grande parte obsoleto. As pessoas não apenas são levadas a mudar várias vezes de profissão em sua vida, como também, no interior da mesma 'profissão', os conhecimentos têm um ciclo de renovação cada vez mais curto (três anos, ou até menos, em informática, por exemplo)" (LÉVY, 1996, p. 54).

Dessa forma, exige-se que as pessoas aprendam, transmitam e passem a produzir conhecimentos, os quais, por sua vez, se tornam novas fontes de riqueza. Isto é, a riqueza de qualquer nação dependerá da capacidade de pesquisa, de inovação, de aprendizado rápido e de cooperação ética entre as pessoas.

Diante disso, a "informação e os conhecimentos passaram a constar entre os bens econômicos primordiais" (LÉVY, 1996, p. 55) numa economia regida por bens de troca. Essa premissa proporciona o tratamento do conhecimento como qualquer outra mercadoria industrial. O autor referido afirma que é um sistema regido pela economia da raridade, pois, quanto mais escassos os produtos, mais caros ficam e quanto mais abundantes, mais baratos. Cria-se, então, um paradoxo, pois o conhecimento é algo que não se estoca; quanto mais se usa, mais novo fica; mesmo compartilhando, não ficamos sem. Essas são características da economia da abundância ${ }^{8}$.

Contraditoriamente, mesmo estando em uma economia da abundância, agimos como se estivéssemos em uma economia da raridade. O discurso do domínio não privilegia a produção intelectual, pois se preocupa mais em fixar tecnologias e menos em elaborar conhecimentos. Assim, valoriza apenas um saber informático em sua perspectiva operacional e recorre apenas ao domínio e à multiplicação de tecnologias de "última geração".

\footnotetext{
${ }^{8}$ Neste caso, podemos citar como exemplo o movimento da comunidade defensora do software livre.
} 
As pessoas geralmente utilizam determinados programas por estarem na "moda", certamente ditada pelo marketing estratégico e pela publicidade. Assim, essas empresas podem limitar o lançamento de tecnologias novas, mantendo por mais tempo determinadas tecnologias, apesar de suas ineficiências e, às vezes, do lançamento de novos produtos que dão guinadas bruscas para o totalmente novo ${ }^{9}$.

Esta é uma característica da globalização perversa, que é o ápice do processo de internacionalização do capitalismo, o qual, segundo Milton Santos, produz nas pessoas, de forma artificial e acelerada, um sentimento de necessidades, seguido de uma consciência da escassez, pois "aquilo que falta a mim, mas que o outro mais bem situado na sociedade possui" (SANTOS, 2001, p.129) leva, a cada lançamento de um produto, as pessoas a sentirem necessidade do "novo".

Dessa forma, o controle dos fluxos proporciona a formação de verdadeiros cartéis, ou empresas de caráter monopolista, que organizam o controle desses fluxos, e, é claro, do mercado, podendo acelerar ou desacelerar o lançamento de produtos. A estratégia dessas empresas é a transformação do produto mais do que a especialização da produção (DELEUZE, 1992), que tem como consequência uma dinâmica produtora de desorientação. Essa estratégia permite que as corporações controlem o ritmo de produção do conhecimento. Passam a ditar, automaticamente, as regras de desenvolvimento de determinadas regiões, conforme interesses próprios, não tendo interesse pela introdução do estudo da computação na educação básica, justamente porque essa oferta representaria uma reabilitação do conhecimento da informática, como não-propriedade.

\section{Referências}

APPLE, Michael. Trabalho docente e textos: economia política das relações de classe e de gênero em educação. Porto Alegre: Artes Médicas, 1995.

CASEMENT, Charles; ARMSTORNG, Alison. A criança e a máquina: como os computadores colocam e educação dos nossos filhos em risco. Porto Alegre: Artmed, 2001.

${ }^{9}$ Como adverte Deleuze (1999), não devemos identificar o novo pela moda e sim pela criação. 
CASTELLS, Manuel. A sociedade em rede. 2. ed. São Paulo: Paz e Terra, 2000.

DELEUZE, Gilles. Post-scriptum sobre as sociedades de controle. In: Conversações. Rio de Janeiro: Editora 34, 1992.

DELEUZE, Gilles. Bergsonismo. Rio de Janeiro: Editora 34, 1999.

DEMO, Pedro. Professor do futuro e reconstrução do conhecimento. Petrópolis: Vozes, 2004.

FAZENDA, Ivani. Interdisciplinaridade: um projeto em parceria. $2^{\mathrm{a}}$ ed. São Paulo: Loyola, 1993.

HUIZINGA, Johan. Homo Ludens: o jogo como elemento da cultura. São Paulo:

Perspectiva, 1993.

LÉVY, Pierre. As tecnologias da inteligência: o futuro do pensamento na era da informática. Rio de Janeiro: Editora 34, 1993.

LÉVY, Pierre. O que é virtual? São Paulo: Editora 34, 1996.

LÉVY, Pierre. A máquina universo: criação, cognição e cultura informática. Porto Alegre: Artmed, 1998a.

LÉVY, Pierre. Tecnologias intelectuais e modos de conhecer: nós somos o texto. 1998b.

Disponível em: <http://empresa.portoweb.com.br/pierrelevy/nossomos.html> Acesso em: 25 mar. 2012.

LÉVY, Pierre. Cibercultura. São Paulo: Ed. 34, 1999.

MACHADO, Nilson José. Matemática e Realidade. 3. ed. São Paulo: Cortez, 1994.

MACHADO, Nilson José. Matemática e educação: alegorias, tecnologias e temas afins. 4. ed. São Paulo: Cortez, 2002.

MACHADO, Nilson José. Conhecimento e valor. São Paulo: Moderna, 2004.

SANTOS, Milton. Por uma outra globalização: do pensamento único à consciência universal. 6. ed. Rio de Janeiro: Record, 2001.

SANTOS, Santa Marli Pires dos (org). O lúdico na formação do educador. Petrópolis: Vozes, 1997. 
SCHAFF, Adam. A sociedade informática: as consequências sociais da segunda revolução industrial. 3. ed. São Paulo: UNESP, 1992.

SERRES, Michel. Novas tecnologias e sociedade pedagógica: uma conversa com Michel Serres. 2000. Entrevistadores: Rogério da Costa e Ricardo Teixeira. Disponível em: <http://www.interface.org.br/revista6/entrevista1.pdf>. Acesso em: 28 jun. 2012.

TENÓRIO, Robinson. Computadores de papel: máquinas abstratas para um ensino concreto. 2. ed. São Paulo: Cortez, 2001.

UNESCO. O perfil dos professores brasileiros: o que fazem, o que pensam, o que almejam. São Paulo: Moderna, 2004.

Recebido em: 25/06/2013 Aprovado em: 26/09/2013

Universidade do Estado de Santa Catarina - UDESC Programa de Pós-Graduação em Educação - PPGE Revista Linhas Volume 14 - Número 27 - Ano 2013 revistalinhas@gmail.com 